\title{
3 \\ Production decisions and time allocation: a guide to data collection
}

RAYMOND HAMES

\section{INTRODUCTION}

In this chapter I deal with methods for collecting behavioral and economic data on productive inputs and outputs. Any attempt at the collection of quantitative data requires that the researcher should ideally have prior knowledge of the full range of economic activities and perform preliminary evaluations of the accuracy of data collection procedures and coding schemes. This will prevent false starts, increase cross-cultural comparability, and lead to a more systematic account of activities. Whenever possible, I encourage researchers to rely on observational data as a kind of gold standard: it produces data amenable to sophisticated quantitative analysis, is crucial for theory testing, is more easily used for cross-cultural comparison than qualitative observations, and reduces the known errors in recall data (see Stange et al. 1998 for an illuminating account of recall errors compared to direct observation). Nevertheless, because of intrusiveness, labor intensiveness, and cultural sensitivities in direct observation, recall data are oftentimes required, but may be integrated into behavioral records. Techniques for reducing recall error (e.g., short time frames) and crosschecking are recommended in such cases.

Conventionally, economic activities may be defined as behaviors whose end result is the production of a material good (e.g., food or artifact), maintenance of an object (e.g., tool repair), or provisioning of a service (e.g., assisting a neighbor building a house). Production activities can be easily characterized along a set of input measures (time, 
energy, or even risk) but output measures are more complex. In food production outputs are conventionally weight, kilocalories, or macronutrients (carbohydrates, fats, and proteins) and represent common denominators for comparative and analytic purposes. Which of these currencies is appropriate will depend on the research question posed.

However, in non-market economies without exchange value currencies there are many common productive activities that are difficult to reduce to a common output denominator even though they have clear economic values (water and fuel collection). If one works to collect and mash nara (a Yanomamö term for a red plant pigment used as a cosmetic) or builds a musical instrument then the output is red coloring or a flute. The only common denominator they have with other economic activities is the time and energy it takes to produce them. But time and energy are limited, and the ability to produce such goods may demonstrate that one has sufficient margin in food and other necessary kinds of production to spend time in other kinds of production. Employing costly signaling theory, Bliege Bird and Smith (2005) propose that the production of some goods (e.g., elaborate houses or flutes) serves to signal personal attributes ranging from "physical vigor to cognitive skills to coalition size and cohesion. While the precise benefits to signalers and receivers have not been measured in most cases, the leading contenders include obtaining better mates, forming valuable alliances, and avoiding the costs of violent competition." (p. 237). The hypothesis, then, is that "luxury" goods production demonstrates that the individual is easily able to produce life essentials (akin to Veblen's [1899] “conspicuous consumption”).

Costly signaling analyses show that what constitutes economic or productive data has broadened over the years, especially with the introduction of evolutionary approaches to human ecology. In behavioral ecological analyses the focus is on activities that lead to the growth, reproduction, and maintenance of offspring and relatives. Therefore, what constitutes productive activities is much broader, since it can include such things as the care of offspring or the cultivation of inedible trophy yams (Bliege Bird and Smith 2005: 228). In addition, as will be shown below, behavioral ecology is also concerned with the development of economic competencies among children and therefore does not restrict itself to the activities of adults. The advantage of behavioral observation in its focus on the behavior of individuals, regardless of what they may be doing (except in the case of focal follows described below) or how old they are, is that it leads the researcher to describe behavior more comprehensively. Such an 
inclusive approach allows an analyst, whatever his or her theoretical persuasion, to select which behavior he or she wishes to classify as economic so long as codes are reasonably detailed for all behavior (an issue discussed below). This broadens the appeal and cross-cultural power of behavioral observations.

In the pages below I describe current techniques used to collect input and output production data, the strengths and weaknesses of different approaches, and ways to insure the collection of an unbiased sample. In addition, I show how techniques of behavioral observation have been artfully extended to include ways to measure labor and resource exchanges as well as environmental impacts of subsistence activities.

OBSERVATION AND RECALL

A researcher can acquire quantitative data on time allocation through direct observation or through informant recall. The method one chooses will depend on a complex set of factors, and each approach has particular strengths and weaknesses. Informant recall, sometimes called the time diary method or 24-hour recall, requires informant literacy and familiarity with a 24-hour day. At the end of the day, an informant is asked to record all activities typically divided into halfhour time increments. Reseachers collect these subject-generated forms on a regular basis. This approach is standard among sociologists and others who work in literate societies (Paolisso and Hames 2010). In many ethnographic contexts this method is difficult to implement since local notions of time of the day are not easily divisible into halfhour intervals, and even if the population is literate, use of forms based on general Western cultural concepts may prove difficult to implement. Alternatively, recall could be generated by interviewing informants at the end of the day (e.g., Aspelin 1979). This is not to say that recall methods should not be used; rather their uses are limited to specific activities. Those interested in an extensive discussion of the strengths and weakness of each method should consult Paolisso and Hames (in press). Here we focus exclusively on observational techniques and reveal that they occasionally rely on informant recall.

DIRECT BEHAVIOR OBSERVATION

There is a robust literature on various techniques of direct behavior observation. General reviews are found in a classic paper by Altmann 
Basic Observational Techniques

\begin{tabular}{|c|c|c|c|}
\hline \multicolumn{1}{|c|}{} & \multicolumn{2}{c|}{ Sampling Rules } \\
\cline { 2 - 4 } & \multicolumn{1}{|c|}{ Group } & Individual \\
\cline { 2 - 4 } $\begin{array}{c}\text { Recording } \\
\text { Rules }\end{array}$ & $\begin{array}{c}\text { Instantaneous } \\
\text { (event) }\end{array}$ & $\begin{array}{c}\text { Instantaneous } \\
\text { scan }\end{array}$ & $\begin{array}{c}\text { Instantaneous } \\
\text { focal }\end{array}$ \\
\cline { 2 - 4 } & $\begin{array}{c}\text { Continuous } \\
\text { (state) }\end{array}$ & $\begin{array}{c}\text { Continuous } \\
\text { scan }\end{array}$ & $\begin{array}{c}\text { Continuous } \\
\text { focal }\end{array}$ \\
\hline
\end{tabular}

Figure 3.1 Sampling and recording rules in behavior observations.

(1974) and in Martin and Bateson's (1993) textbook with a focus on psychology and ethology, and in anthropological applications by Gross (1984), Johnson and Sackett (1998), Borgerhoff Mulder and Caro (1985) and Hames (1992). By direct observation, I mean observations that are generated by a researcher. As with recall research, the goal of direct observation is to collect a wide variety of quantitative data on behavior that can be used to statistically test hypotheses or to more precisely describe patterns of behavior. It may lead to the discovery of patterns of behavior that may not have been apparent to the observer or subject, and it may completely reverse an ethnographer's subjective perceptions of what occurs on a daily basis (Erasmus 1955).

Following Martin and Bateson (1993: 84-86), I distinguish between sampling rules (who or what is observed) and recording rules (whether behavior is recorded continuously or instantaneously). Any behavior measurement is a combination of a sampling rule and a recording rule. A simplified picture of how sampling and recording rules are combined is presented in Figure 3.1 (see Martin and Bateson 1993: 88, Figure 6.1 for a more elaborate scheme). ${ }^{1}$ I will briefly characterize the logic behind using different sampling rules and then turn to a much more detailed consideration of recording rules reflecting dominant ethnographic interest and research.

\footnotetext{
${ }^{1}$ I do not discuss ad libitum sampling, a kind of behavior sampling, which involves the unsystematic recording of "interesting" behaviors and is only useful for initial investigation or, perhaps, rare but important events.
} 
A researcher can elect to sample either a behavior itself or individuals or groups. If a behavior is selected (termed behavior sampling or "one-zero") then one records whether or not a particular behavior occurred during a recording period. Who is sampled is solely determined by whether the individual expresses the behavior. This procedure can be done on individuals or groups. Once the group or individual (or even place) is selected and the sampling period is determined (e.g., a 10 minute block of time) the observer selects a time interval (e.g., every minute) and records whether the behavior occurs or does not occur (hence one-zero, or yes-no) independent of how many times it occurred. Like instantaneous sampling (see below) the unit of observation is dimensionless. So long as the sampling intervals are short (e.g., sampling every minute versus every 5 minutes) this method produces reasonably accurate measures (Martin and Bateson 1993: 55).

Behavior sampling is useful for recording behaviors that are rare but significant and would be otherwise missed using alternative sampling and recording schemes, although it is sometimes used in conjunction with other sampling and recording rules. Behavior sampling is frequently used in primatology (e.g., Mitani and Watts 2005) to study crucial behaviors such as agonistic interactions, grooming, and sex that researchers believe are central for understanding social relations, status position, dominance and subordination, and reciprocal relations. However, it is rarely used by ethnographers (see Marlowe 2005 on parental care of Hadza children for an exception).

If one makes individuals the unit of observation then one must decide whether to focus on a group or an individual. Focal sampling is employed when the focus is on a single individual for an extended period of time (focal observation or a focal follow). The individual's behavior may be recorded instantaneously or continuously (see below) within a particular time frame. This does not mean that others with whom the focal individual interacts are not necessarily recorded. In contrast, in scan sampling one observes a group with several individuals who are in close enough spatial proximity for them to be recorded simultaneously (group observation, with dyads being the most common). Scan observations pose obvious difficulties in terms of a researcher's ability to accurately monitor the behavior of more than one individual. This limitation is made more severe if one attempts to make continuous observations instead of instantaneous observations. Scan observations are limited to closely interacting dyads such as a parent and offspring (Ivey 2000; Ivey Henry et al. 2005; Fouts and Lamb 2005) or spatially delimited groups, such as a group involved 
in a ritual, a shouting match (Flinn 1988) or cooperative agricultural labor (Hames 1987). A solution to the problem of attempting to record more than several individuals on a continuous basis would be to use video equipment to record group members, followed by review of the video to carefully extract data for analysis, as in Takada's (2005) work on mother infant interactions among !Xun foragers. An alternative strategy of observing a group would be to code the behavior very generally. For example, if a group of people were gathered for a ritual performance one could record some of them as watching and others performing instead of more precisely coding behavior as watching while talking, waiting to perform while watching, or performing a specific ritual act.

Clearly use of focal or group sampling depends on the research question posed and the recording rule (see below) employed. If one is interested in detailed and sequential characterization of a behavior or a behavior complex (e.g., details of hunting when it is necessary to code for travel, search, rest, pursuit, and return) regardless of social context (e.g., Bliege Bird and Bird 2002) or how much time is allocated to foraging is particular locations (Aswani 1998 on Pacific fishing), then focal sampling is best, while group sampling is the method of choice when the emphasis is on social interaction or the collection of population level measures on age and sex differences.

\section{RECORDING RULES}

Recording rules are of two broad kinds. Continuous recording is the moment-by-moment description of certain behaviors within a fixed time interval. It is fine-grained and permits measurement of duration, latency, and other measures discussed below. Instantaneous sampling, as the name suggests, simply records the behavior of the individual the instant he or she is observed. It is a "dimensionless" measure since it has no duration. As such, the only statistics that can be compiled are counts of the various behaviors recorded, but such counts can be legitimately transformed into real time measures under certain conditions and with certain assumptions. For example, if one samples behavior during waking hours, say a 14-hour day, and one knows that 15 percent of observations were in food preparation activities, then one could reasonably conclude that 2.1 hours per day were spent in this activity. (Of course, this assumes that this behavior only occurs during the daylight sampling period, see Scaglion 1986 on nighttime sampling) Although simple counts may seem like a severe limitation, 
instantaneous (commonly called instantaneous scan sampling) is the most commonly used recording method in anthropology, for a number of reasons I will describe below.

A way to conceptually differentiate between continuous and instantaneous recording is to think of continuous sampling as akin to recording behavior with a video camera while instantaneous records behavior uses a still camera. I will first begin with a characterization of strengths, weakness, and appropriateness of continuous recording and follow it with a consideration of instantaneous recording. Since instantaneous recording is by far the most commonly used technique in anthropology I will present a more detailed examination of the methodological literature behind it and novel extensions of the technique.

\section{Continuous recording}

Continuous recording is employed whenever the research question requires detailed information on multiple dimensions of behavior. Under continuous recording the following dimensions of behavior may be collected:

- $\quad$ Frequency: how frequently a behavior occurs within a particular time period

- Intensity: how energetically or forcefully the behavior is acted. There are numerous field and laboratory experimental studies (e.g., Hipsley and Kirk 1966; Durnin and Passmore 1967; Montgomery and Johnson 1976) that can be adapted to one's field data to create good estimates of caloric expenditures of effort

- Latency: the period of time prior to the onset of a behavior

- Duration: how long a behavior lasts

- Sequence: the ordering of behaviors through time or in relation to external contexts

\section{Instantaneous recording}

As mentioned, instantaneous recording only permits the collection of behavior frequency and intensity while continuous recording allows one to collect all of the above dimensions of behavior. At first glance it would seem obvious that continuous recording would be the best choice; but continuous recording has a number of limitations. As I 
have already mentioned, it is normally linked to focal sampling, making it extremely difficult to record the continuous behavior of more than one individual at a time unless the individuals are immediately adjacent to one another (as is the case, for example, in studies of parent-infant interactions). The second problem is that it is very intrusive, such that a subject may alter his or her behavior when observed on a continuous basis at close quarters. The third is that it is very expensive of a researcher's time. Quantitative analysis depends on a reasonably large sample of individuals in different contexts and at different times of the day and who have an adequate range of demographic qualities (old, young, female, male). Gaining a representative sample using continuous sampling is thus difficult for a single researcher. But for certain kinds of questions such a method is indispensable. For example, if one is concerned with how responsive parents are to infant vocalizations, duration of nursing bouts, and responses to fretting and crying (Konner and Worthman 1980; Fouts and Lamb 2005) then continuous observations are required. By way of contrast, if one's research question is who cares for infants and toddlers then instantaneous sampling will provide richer data (the full range of caretakers under a variety of conditions) at a much lower cost of researcher time (Hames 1988; Marlowe 2005; Henry Ivey et al. 2005). For a good sample of research on childcare using both methods, singly and in combination, see the volume edited by Hewlett and Lamb (2005).

In many instances a researcher may benefit from using both instantaneous and continuous sampling procedures. For example, Marlowe (2005) and Bird and Bliege Bird (2005) used a combination of instantaneous and continuous methods to study care-taking and the foraging activities of infants and children respectively. The goal of these studies was to generate general time allocation data on a large number of individuals coupled with more precise measures of specific activities and patterns of parent-infant interaction.

Commonly called "spot checks" (after Johnson 1975), "scan sampling” or "instantaneous scan sampling” (Borgerhoff Mulder and Caro 1985; Hames 1988), instantaneous recording is by far the most commonly used method of behavior sampling in ethnography. The procedure consists of recording a subject's behavior the moment the subject is observed at randomly determined intervals. Additionally, as in other approaches, one often notes contextual information such as location, the presence of other individuals, date, and time of day. In village-based ethnographic studies it usually consists of serially visiting households in a village or section of a village and recording the 
behavior of everyone present at the moment (instant) that the individual is viewed by the ethnographer. After the recording is done the ethnographer proceeds to the next house and repeats the procedure until the entire village is sampled (but see below on "block sampling").

Instantaneous recording has considerable popularity among ethnographers from a variety of theoretical perspectives. Under the leadership of Allen Johnson, numerous researchers who had collected data employing instantaneous recording contributed to the establishment of a time allocation digital database and universal coding scheme along with cultural descriptions (Johnson 1990). ${ }^{2}$ Instantaneous recording has a number of advantages. It is very economical in terms of an ethnographer's research time. An outcome of the economy of the approach is that it permits a large number of different individuals to be sampled. Frequently, all members of a village of more than 100 individuals, which more easily permits an analyst to ask questions about differences in behavior as they vary by age, social status, and sex. In some cases, over the course of a year some ethnographers have made more than an average of 300 observations per person in a village of more than 100. Finally, it is less obtrusive to subjects, such that they are less likely to modify their behavior compared to the constant scrutiny of continuous observation. In continuous observation, researchers may literally dog the footsteps of their informants to collect behavioral information.

METHODOLOGICAL ISSUES AND PROBLEMS

In recent years methodological reports have emerged where researchers describe problems they have encountered in using behavior observations, and their solutions. These studies candidly assess the practical, methodological, and observer effects that may not be apparent to a neophyte. In these methodological reflections, the goal is to ensure the accurate and unbiased collection of data through self-criticism. More specifically, Hawkes et al. (1987) deal with the problem of overestimating the frequency of easily visible group behavior, Betzig and Turke (1985) on intentional versus observed behavior, and Borgerhoff Mulder and Caro (1985) on a variety of problems such as coding, seasonal and diurnal patterns, verbal reports, and inter-observer reliability. Johnson and Sackett (1998) along with Borgerhoff Mulder and Caro

\footnotetext{
${ }^{2}$ A full list of the publications from this project are available at http://www.yale.
} edu/hraf/publications_body_completepublist.htm\#Time\%20Allocation\%20Series 
(1985) are two sources anyone planning to use behavior observations should read; they provide an excellent summary of problems, options, and solutions in a wide variety of situations.

\section{Observational problems}

A researcher should always strive to observe behaviors candidly, develop techniques that ensure that all relevant behaviors have an equal opportunity to be observed, and that the presence of the observer and the methods used do not affect the behavior of the observed. Of course, a culture's preferences for privacy, openness, and observability may require the researcher to modify these requirements tactically in order to achieve an unbiased sample of observations. In many cultures it is inappropriate for a researcher to unexpectedly enter a house to observe behavior even though unpredictability (to the observed) ensures that what is observed is not modified in anticipation of the ethnographer's presence. In other instances, restrictions owing to the observer's or subject's sex or social status may create problems.

In many instances the goal of instantaneous sampling is the creation of a random sample of a large number of subjects representative of all social divisions. Although a large sample size is always desirable, improperly building it may lead to bias. Peregrine et al. (1993) illuminate this point. They used a video tape recorder to create a 32-hour continuous record of activities of preschoolers in a nursery setting. Using that continuous record as the base, they drew samples analogous to those employed by ethnographers using behavioral observation techniques. They found that attempting to make longer observations (recording all behavior for a 1-hour period instead of numerous visits of shorter duration totaling 1 hour) led to results that deviated significantly from the 32-hour record. This and other studies clearly indicate that in order to generate a random sample a researcher must be able to make observations at any time of the day, under all conditions, and independent of social situations. More to the point, researchers may be unaware of how choices made about when, where, and who to sample may lead to sampling biases. If a researcher chooses subjects, times, or locations because of cooperativeness or convenience then bias may be introduced (Borgerhoff Mulder and Caro 1985: 325). It is clear that no ethnographer has free and instantaneous access to all individuals in their sample. Consequently, purely random observations are difficult. Nevertheless, there are a variety of procedures that one can use to ensure as close to a random sample as possible. 
In some small communities it is feasible to include all households in a single sampling round making instantaneous observations very economical. However, if households are widely dispersed across the landscape, travel time becomes so great that it is inefficient to attempt to observe all households in a single sampling round. Block sampling is designed to overcome this problem, and was first devised by Behrens (1981). He divided the households in his Shipibo community into several contiguous household clusters separated from one another by several kilometers. He stayed in each cluster for 4 hours and sampled all households in the cluster every 30 minutes (for a similar procedure see Gurven and Kaplan 2006). Block sampling is obviously useful in an urban context where subjects may be widely dispersed.

All researchers have faced the problem of showing up to make observations only to discover that the subject or subjects are not present. One solution to the problem is to simply ask someone who should know (e.g., a present household member) to report where the subject is. The report is then used as an "observation" when in reality it is a report. If so, the researcher should record this fact (Borgerhoff Mulder and Caro 1985). Whether or not such second-hand information can be used depends on the accuracy of reports and the degree to which such reports have sufficient resolution to satisfy research goals. The correspondence between reports and actual behavior should be ascertained prior to research and monitored during research. In one study, for example, at the end of the day I tracked down individuals on whom reports had been given and asked them what they were doing at the time when the report was generated (Hames 1979). I found a greater than 95 percent correspondence between reports by others and the subject's own recall. Consequently, I felt that reports were reliable but continued to periodically check the accuracy of reports by interviewing those reported on at the end of the day.

Observations, whether continuous or instantaneous, are typically made during daytime hours and sometimes extend into early evening or morning. In many places sampling during nighttime hours is either dangerous or unwelcome. In a pioneering piece of research, Scaglion (1986) sampled behavior during nighttime hours (7:00 p.m. to 6:00 a.m.) and discovered that in 26 percent of observations his New Guinea subjects were awake, and in approximately 75 percent of these instances they were engaged in ritual activities. When nighttime observations are pooled with daytime observations and then compared to daytime observations, some underestimates and overestimates of behaviors are evident (see Scaglion, 1986, Table 4: 542). Researchers 
must determine the importance of nighttime activities, and modify their observational hours accordingly.

\section{Coding Problems}

Recording a behavior classified as an instance of " $\mathrm{X}$ " entails a coding decision. Issues in coding seem to resolve around three major issues: (1) the problem of simultaneity; (2) what and how finely to code; and (3) functional versus structural descriptions. To the uninitiated, nothing could seem easier that describing the behavior of another. Having to do so in rapid-fire sequence can be a humbling experience, however. For example, in observing the Ye'kwana it was not uncommon for me to come upon a woman sitting on the lever of a manioc press (to express the juice from the pulp) while nursing a child and conversing with an adjacent woman. How should I code what was she doing? Johnson and Sackett (1998: 327) call this the simultaneity problem, and describe the strengths and weaknesses of six possible solutions. All the solutions are reasonable, but the one I favor is to code the behaviors as primary, secondary, and tertiary, thus preserving the richness of the observation. This creates another problem: which behavior is primary, etc. Context can help one decide. In this case the woman had gone to the press to express the juice. So a particular kind of food preparation would be the primary activity. She had brought her child with her which makes childcare a secondary activity. Another woman happened to be there, so conversation becomes the tertiary activity. Preservation of such complexity may be cumbersome, but I believe it is worth the effort. For example, in the case above, if one were interested in knowing who cares for children, valuable data would be lost if the mother's secondary behavior was not recorded.

Researchers should carefully consider the problem of behavior coding even if economic behavior is their sole interest. The first thing to realize is that any code is an abstract and limited characterization of a complex act. Furthermore, researchers should not neglect careful classification of so-called non-economic behavior because different research questions may have a more expansive definition of economically productive behavior. A good example of this is seen in Lee's initial measures of work among the San when he documented that they worked but 2.2 to 2.4 hours per day, a figure widely cited in the literature. However, Lee restricted his definition of labor to direct food production (hunting and gathering) and left out much of what is arguably a more reasonable array of economic activities such as food 
processing, artifact production, and fuel and water collection. When all these activities were added, labor time jumped to 6.4 hours per adult day in Lee's fuller account (1979). A solution to this problem is to make random observations of behavior such that the behavior of a subject is recorded independently of what the subject is doing. If one follows the standard protocols outlined above for continuous or instantaneous recording, then all behaviors will be recorded and an analyst, given his or her research interest, can decide what to include or exclude as relevant economic behavior.

How behavior is described is critical for cross-cultural comparisons. Whether one employs functional versus structural descriptors in codes (following Hames 1992) or descriptions by consequence or physical descriptions (following Borgerhoff Mulder and Caro 1985) is an important issue. Structural/physical codes describe the bodily actions, stances, orientations, etc. of the observed, and can be quite detailed since one may be describing a very complex pattern of behavior. Functional/consequence codes focus on the purpose or design of the behavior, are simple, and conform to our intuitive understanding of behavior. For example one might structurally describe a behavior as squatting on the ground while striking plants with a machete at ground level, and occasionally tossing plants into a pile. Functionally, one would write "weeding." Coding structural descriptions is akin to writing a telegraphic sentence (e.g., squat, machete, swing, toss plant) which can make analysis difficult. Functional codes like "weeding" are more tractable. But sometimes our intuitions regarding function may be highly inaccurate, particularly in novel cultural environments. Accurate functional descriptions presuppose that the researcher has an excellent grasp of local behavioral intentions and variability and it is therefore imperative that a researcher takes time to ask informants about what he or she is observing. An excellent discussion of this problem can be found in Borgerhoff Mulder and Caro (1985: 327-328) and should be read by anyone planning behavior observations. One solution to the problem is to double code the behavior following structural and functional rules.

Finally, another dimension of coding is how finely codes are constructed. I believe the best procedure is to code behavior as finely as practicable, using a hierarchical scheme. For example, one could call a variety of related behaviors "food preparation" without coding for the kind of food or the preparation step involved. But lack of detail causes the loss of valuable information and the corresponding inability, for example, to answer the simple question of what food resource 
demands the most processing and which step is the most time consuming. Bock (2002) and Gurven and Kaplan (2006) made analytic use of such detail to assess the roles of strength and skill in the allocation of labor activities through the life course. Johnson and Sackett (1998) propose a flexible and widely used cross-cultural coding scheme used by many.

BEYOND SIMPLE BEHAVIOR: TIME, LOCATION, INTERACTION, AND RESOURCE FLOWS

Many assume that behavior observations are primarily designed to provide static or dynamic information on basic activities broken down by social attributes (e.g., sexual division of labor). However, the strength, flexibility, and utility of behavior observations goes far beyond the recording of an individual's behavior in its simple behavioral and time coordinates. Many interesting questions can be quantitatively answered depending on how one constructs the data record as well as what time and space mean in a specific cultural context. For example, Sugawara (1988) used the location variable to document gender differences in inter-camp visiting among San foragers, and Ohtsuka et al. (2004) were able to use the location variable to understand gender-based differences in exposure to environmental toxins. Winking et al. (2009) used the location variable to determine the conditions under which husbands assist wives in childcare. Below I show how detailed recording of locational and other variables open new areas of research through behavioral observations.

A location variable is useful for a variety of questions that focus on whether the behavior is done inside or outside the home, or individually or collaboratively. Use of a location variable depends on what location may mean for a particular group. For example, Hames (1987) used the location to determine whose garden an individual was working in order to create measures of garden labor exchange among the Ye'kwana. In another study (Hames and McCabe 2005) on the Ye'kwana, the location variable was used to measure meal sharing patterns. In both cases, when someone was observed to work in a garden not his or her own or eat a meal in another household, the owner of the field or household was known, and these cases were scored as measures of labor and food exchange, respectively. Yasuoka's work (2006) is a particularly excellent example of how behavior observationstied to locational information can be employed to answer important ecological questions such as the ability of Pygmy populations to 
forage independently of horticulturalists. There are many other uses of the locational variable that have to do with basic patterns of association that may be used to characterize fundamental aspects of social organization and networks. Below are further examples of uses of quantified behavioral observations beyond standard time allocation accounts.

Instantaneous recordings have been employed to study the flow of food resources between individuals and families, a fundamental dimension of economic organization. The method was pioneered by Kaplan et al. (1984) in a study of resource sharing among Ache huntergatherers and replicated in many other studies (see Gurven 2004 for a review). The traditional method for studying food exchange is for the researcher to interview household members and ask them to recall food received or given from or to other households during specific time intervals (e.g., Aspelin 1979), or to make direct observations of distributions (Hames 1990). Although these techniques have important advantages (e.g., accurate information on weights or volumes given and received), they also have limitations. They rely on recall which may be inexact, provide no measure of how much each family member is impacted, and miss many of the casual and spontaneous exchanges that are common in many societies, such as meal sharing (Hames and McCabe 2007). While recording instantaneous observations in an Ache camp, any time an individual was observed to eat, researchers (Kaplan et al. 1984) asked the food consumer who gave the food and who produced it (through hunting or gathering). This allowed them to effectively measure the flow of food resources, many of which would not have been captured by traditional methods. Since eating is a common activity and the Ache share a great deal, sample size was large enough for extensively detailed analysis as it related to a whole host of variables relevant to testing different theories of exchange.

\section{ESTIMATING PRODUCTION}

Using a life historical perspective, time allocation techniques have recently been applied to investigating the (sex-specific) age at which humans achieve self sufficiency (producing as much as they consume), what qualities must be achieved (strength, skill, and knowledge) to make this transition to a productive adult, and the degree to which families can satisfy their consumptive needs over the demographic cycle. In investigating these questions researchers have developed 
more intensive techniques to measure variation in productivity and have extended their analyses to all age groups.

Problems associated with measuring production differ between immediate return activities (foraging) versus delayed return activities (agriculture and pastoralism). Furthermore, accurately measuring production is difficult because it can vary dramatically depending on age and sex. Consequently, simple time allocation measures are usually not adequate proxies for production (Bird and Bliege Bird 2005; Bock 2002; Gurven and Kaplan 2006). Early research on hunting, for example, used a combination of interviews and direct measurement of production (e.g., Lee's well known studies of San foraging productivity $(1968,1969)$ to calculate measures of economic performance). Hunters were interviewed at the end of the day or every week to ask how long they hunted and what they captured or even how many large animals they had taken in the last year. Alternatively, some researchers collected instantaneous data on all activities and coupled them with daily interviews to measure hunting yields (Hames 1979). While these approaches are satisfactory for certain kinds of activities and their efficiency in data collection can generate large samples, they may be problematic. Hunters may over- or underestimate what they acquired, fail to include the assistance of others, make divisions after a kill, or may not note that hunting was combined with other activities.

Today, focal follows coupled with weighing of acquired resources are increasingly employed to gain very precise output/input measures, especially as it relates to changes in efficiency over the life course. Using focal follows and continuous sampling, Bird and Bliege Bird (2005) were able to collect data on the foraging productivity of all Meriam aboriginals. Collecting this fine-grained data is time-consuming. Bird and Bliege Bird (1997; 2005: 244) made 358 focal follows on 75 individuals between the ages of 4 and 75 for a total of 518 hours of foraging observation. During each of the continuously observed focal follows they collected a large array of data such as tools used, weight of resources taken, successful versus unsuccessful resources acquisitions, and time devoted to searching, travel, and pursuit. This wonderfully fine-grained research permitted them to answer critical questions revolving around the productivity of children and adults as it relates to strength and endurance or the development of skills that pay-off in enhanced adult productivity as well as how foraging choices made by children differed from adults yielding a nuanced test of diet breadth. 
In delayed-return activities such as horticulture and pastoralism, estimating production for individuals is far more difficult. This is because total production inputs represent a series of interconnected activities over a long time period, often characterized by a division of labor such that numerous individual are responsible for each stage of production, while the ultimate outputs may occur months after the original inputs. In horticulture it is common for men to clear fields, women to plant; both may harvest, and women process the food for immediate consumption and storage, but women and men do these tasks at different efficiencies. In addition, the costs of tool production and maintenance must be factored, which may be difficult since many tools are multi-purpose (a machete can be used to butcher meat, cut thatch, slash undergrowth, weed a garden, etc.). A simplified solution to this problem promoted by Kramer (2002: 311) is the use of discount coefficients for various tasks required in agriculture (see also Kaplan 1994 and Gurven and Kaplan 2006). Using continuous observations, she examined the rate of work accomplished in a variety of fundamental productive tasks by children at several age intervals and adults (Kramer 2005: 194). For all but the simplest activities the efficiency of children was considerably less than adults. The next step was to estimate the entire caloric needs of the household using standard caloric expenditure references (e.g., Durnin and Passmore 1967) for particular tasks, and then compare this to the net efficiency (resources produced per unit time by different age/sex categories) and daily time allocated to these tasks by household members. Since there is almost no food or labor sharing among the Maya (Kramer 2005: 127) it was assumed that all food consumed by household members was produced by household members.

At this point, this sort of estimation procedure seems to be the best that has been devised for delayed production systems. Kramer (2002: 310) notes that the difficulty in gaining reasonably accurate production estimates is a serious problem. In her own study Kramer notes that 80 percent of labor is for food production, but necessary activities such as drawing water and hauling firewood are not included. Although the Maya engage in little inter-household resource exchange her estimation procedure would be problematic if such exchanges are common, which may be the rule in more traditional horticultural systems (Gurven 2004).

Much hinges on accurate estimates of productivity; variation in age at economic independence (the age at which an individual produces more than he or she consumes) is a critical question in life 
history theory, and of interest to economic and development anthropologist. For example, Kaplan shows (1994: 781-783) that among the Piro and Machiguenga individuals did not achieve economic independence until about the age of 20. Similar approaches have been employed by Kaplan's students and colleagues to generate age-related production and consumption curves for the Hiwi, Ache, and Maya (Gurven and Kaplan 2006). Productivity measures were also critical for establishing the fact that some households (i.e., those with many dependent children) cannot meet their own consumption needs through their own efforts (Gurven and Walker 2006; Hill and Hurtado in preparation). Such families appear to be subsidized by co-resident households, and this finding represents an important new area of research. Just as importantly, behavior measurements on production and consumption have helped toward a better understanding of intergenerational "wealth flows." In development economics and demography, the reigning paradigm has been that poor farmers desire many children so they will have support in their old age. In contrast, the evolutionary theory of parental investment, and research using behavioral observations, showed that even where children were economically productive, the flow of resources was largely from parents to children and grandchildren (Turke 1989; Kaplan 1994). Finally, the question of when and how humans become competent economic producers has spawned a number of high quality studies on time allocation and production oftentimes combining continuous and instantaneous techniques. An entire issue of Human Nature $(2002,13$ : 2) was devoted to examining the development of economic competence.

Behavior observations have been essential in the examination of how humans impact the environment and the related question of conservation among tribal populations. As noted by behaviorally oriented researchers (Hames 1991; Alvard 1998) early claims of conservation were supported by analyses of ideological systems and practices. The assumption was that beliefs guide behavior. However, a variety of studies demonstrated that beliefs had little impact on conserving game resources (Aunger 1994). More to the point, the actuality of conservation depends on patterns of game harvesting. Researchers using behavior observations to examine hypotheses deduced from conservation in diet breadth, prey selectivity, areal patterns of exploitation, and long-term game yields have rather conclusively demonstrated that conservation is exceptionally rare where ever investigated (Alvard 1998; Hames 2007). 
I have attempted to show that direct and indirect behavior observations are important for answering crucial questions surrounding economic production and human environmental impacts. The behavior observation techniques reviewed were initially employed to simply measure time allocation patterns. Through time, the technique has grown in sophistication and it is now employed to measure the exchange of goods and services, the development of productivity through the life course, production data, areal patterns of exploitation, and resource selectivity. The development of behavior observation techniques has been mandated by hypothesis testing from foraging, life history, and other evolutionary theories that require the collection of high quality empirical data. In other scientific arenas researchers have made sophisticated modifications of observational techniques to address issues of sea tenure (Aswani 2002), food consumption surveys (Umezaki et al. 2002), and energy balance in high altitude regions (Panter-Brick 1996). I believe that considerable improvement can be made in behavioral techniques if researchers would more carefully describe the procedures they use so they could be more fully evaluated and more easily replicated by others. To some extent journal page limits prevent this from happening. Be that as it may, I expect that direct observation techniques will be increasingly used as we begin to ever more carefully and fully describe issues in ecological anthropology.

\section{REFERENCES}

Altmann, J. 1974. The observational study of behavior. Behaviour 48: 1-41.

Alvard, M. 1998. Evolutionary ecology and resource conservation. Evolutionary Anthropology 7: 62-74.

Aspelin, L. 1979. Food distribution and social bonding among the Mamainde of Mato Gross, Brazil. Journal of Anthropological Research 35: 309-327.

Aswani, S. 1998. Patterns of marine harvest effort in southwestern New Georgia, Solomon Islands: resource management or optimal foraging. Ocean and Coastal Management 40: 207-235.

Aswani, S. 2002. Assessing the effects of changing demographic and consumption patterns on sea tenure regimes in the Roviana Lagoon, Solomon Islands. Ambio 31: 272-284.

Augner, R. 1994. Are food avoidances maladaptive in the Ituri Forest of Zaire? Journal of Anthropological Research 15: 54-72

Behrens, C. A. 1981. Time allocation and meat procurement among the Shipibo Indians of eastern Peru. Human Ecology 9: 189-220.

Betzig, L. and P. Turke 1985. Measuring time allocation: observation and intention. Current Anthropology 26: 647-650. 
Bird, D. W. and R. Bliege Bird 1997. Contemporary shellfish gathering strategies among the meriam of the Torres Strait Islands, Australia: testing predictions of a central place foraging model. Journal of Archaeological Science 24: 39-63.

Bird, D. W. and R. Bliege Bird 2005. Martu children's hunting strategies in the Western Desert, Australia. In B. Hewlett and M. Lamb, eds., HunterGatherer Childhoods : Evolutionary, Developmental and Cultural Perspectives. New Brunswick, NJ: Transaction Publishers, pp. 129-146.

Bliege Bird, R. and D. Bird 2002. Constraints of knowing or constraints of growing? Human Nature 13: 239-267.

Bliege Bird, R. and E. A. Smith 2005. Signaling theory, strategic interaction, and symbolic capital. Current Anthropology 46: 221-48

Bock, J. 2002. Learning, life history, and productivity. Human Nature 13: 161-197.

Borgerhoff Mulder, M. and T. Caro 1985. The use of quantitative observation techniques in anthropology. Current Anthropology 26: 232-262.

Durnin, J. and G. Passmore 1967. Energy, Work, and Leisure. London: Heinemann.

Erasmus, C. J. 1955. Work patterns in a Mayo village. American Anthropologist 57: 322-333.

Flinn, M. 1988. Parent-offspring interactions in a Caribbean village: daughter guarding. In L. Betzig, M. Borgerhoff Mulder, and P. Turke, eds., Human Reproductive Behaviour. Cambridge, UK: Cambridge University Press, pp. 189-200.

Fouts, H. N. and M. E. Lamb 2005. Weanling emotional patterns among the Bofi foragers of Central Africa: the role of maternal availability and sensitivity. In B. Hewlett and M. Lamb, eds., Hunter-Gatherer Childhoods : Evolutionary, Developmental and Cultural Perspectives. New Brunswick, NJ: Transaction Publishers, pp. 309-321.

Gross, D. R. 1984. Time allocation: a tool for the study of cultural behavior. Annual Review of Anthropology 13: 519-558.

Gurven, M. 2004. To give and to give not: the behavioral ecology of human food transfers. Behavioral and Brain Sciences 27: 120-155.

Gurven, M. and H. Kaplan 2006. Determinants of time allocation across the lifespan: a theoretical model and an application to the Machiguenga and Piro of Peru. Human Nature 17: 1-49.

Gurven, M., H. Kaplan, and M. Gutierrez 2006. How long does it take to become a proficient hunter? Implications for the evolution of extended development and long life span. Journal of Human Evolution 51: 454-470.

Gurven, M. and R. Walker 2006. Energetic demand of multiple dependents and the evolution of slow human growth. Proceedings of the Royal Society, $B$ 273: 835-841.

Hames, R. 1979. A comparison of the efficiencies of the shotgun and bow in neotropical forest hunting. Human Ecology 7: 219-252.

Hames, R. 1987. Relatedness and garden labor exchange among the Ye'kwana. Evolution and Human Behavior 8: 354-392.

Hames, R. 1988. the allocation of parental care among the Ye'kwana. In L. Betzig, M. Borgerhoff Mulder, and P. Turke, eds., Human Reproductive Behaviour. Cambridge, UK: Cambridge University Press, pp. 237-254.

Hames, R. 1990. Sharing among the Yanomamö. Part I: the effects of risk. In E Cashdan, ed., Risk and Reciprocity in Tribal and Peasant Economics. Boulder, CO: Westview Press, pp. 89-106.

Hames, R. 1991. Wildlife conservation in tribal societies. In M. Oldfield and J. Alcorn, eds., Biodiversity: Culture, Conservation, and Ecodevelopment. Denver, CO: Westview Press, pp. 172-199. 
Hames, R. 1992. Time allocation. In E. A. Smith and B. Winterhalder, eds., Evolutionary Ecology and Human Behavior. Chicago, IL: Aldine de Gruyter, pp. 203-236.

Hames, R. 2007. The ecologically noble savage debate. Annual Review of Anthropology 36: 177-190.

Hames, R. and C. McCabe 2007. Meal sharing among the Ye'kwana. Human Nature 18: 1-21.

Hawkes, K., K. Hill, H. Kaplan, and M. Hurtado 1987. Some problems with instantaneous scan sampling. Journal of Anthropological Research 43: 239-247.

Hewlett, B. S. and M. E. Lamb, eds. 2005. Hunter-Gatherer Childhoods: Evolutionary, Developmental, and Cultural Perspectives. New Brunswick, NJ: Aldine de Gruyter.

Hill, K. and A. Hurtado In preparation. Cooperative breeding in South American hunter-gatherers. School of Human Evolution and Social Change, Arizona State University, Tempe, AZ.

Hipsley, E. H. and N. E. Kirk 1966. Studies of dietary intake and the expenditure of energy by New Guineans. Vol. 147. Noumea, New Caledonia: South Pacific Commission Technical paper no. 147.

Ivey, P. 2000. Cooperative reproduction in Ituri forest hunter-gatherers: Who cares for Efe infants. Current Anthropology 41: 857-866.

Ivey Henry, P. K., G. A. Morelli, and E. Z. Tronick, eds. 2005. Child Caretakers Among Efe Foragers of the Ituri Forest. Hunter-Gatherer Childhoods : Evolutionary, Developmental and Cultural Perspectives. New Brunswick, NJ: Transaction Publishers.

Johnson, A. 1975. Time allocation in a Machiguenga community. Ethnology 14: 301-310.

Johnson, A. 1990. Time-allocation research: the costs and benefits of alternative methods. In B. L. Rogers and N. Schlossman, eds., Intra-Household Resource Allocation: Issues and Methods for Development Policy and Planning. Tokyo: United Nations University Press, pp. Chapter 10.

Johnson, A. and R. Sackett 1998. Direct systematic observation of behavior. In H. R. Bernard. Ed., Handbook of Methods in Cultural Anthropology. Walnut Creek, CA: Altamira Press, pp. 301-330.

Kaplan, H. 1994. Evolutionary and wealth flows theories of fertility: empirical tests and new models. Population and Development Review 20: 753-791.

Kaplan, H., K. Hill, K. Hawkes, and A. Hurtado 1984. Food sharing among Ache foragers of Eastern Paraguay. Current Anthropology 25: 113-115.

Konner, M. J. and C. M. Worthman 1980. Nursing frequency, gonadal function, and birth spacing among !Kung hunter-gatherers. Science 207: 788-791.

Kramer, K. 2002. Variability in the duration of juvenile dependence: the benefits of Maya children's work to parents. Human Nature 13: 299-325.

Kramer, K. 2005. Children's help and the pace of reproduction: cooperative breeding in humans. Evolutionary Anthropology 14: 224-237.

Lee, R. 1968. What hunters do for a living: or how to make out on scarce resources. In R. Lee and I. DeVore, eds., Man the Hunter. Chicago, IL: Aldine, pp. 30-45.

Lee, R. 1969. !Kung Bushman subsistence: an input-output analysis. In D. Damas, ed., Ecological Essays, vol. 230. Ottawa: Nat. Museum of Canada.

Lee, R. 1979. The !Kung San: Men, Women, and Work in a Foraging Society. Cambridge, UK: Cambridge University Press.

Marlowe, F. W. 2005. Who tends Hadza children?, In Hunter-Gatherer Childhoods: Evolutionary, Developmental and Cultural Perspectives. In B. Hewlett and M. Lamb, eds., Hunter-Gatherer Childhoods : Evolutionary, Developmental and Cultural Perspectives. New Brunswick, NJ: Transaction Publishers, pp. 177-190. 
Martin, P., and P. Bateson 1993. Measuring Behavior. Cambridge, UK: Cambridge University Press.

Mitani, J. C. and D. P. Watts. 2005. Correlates of territorial boundary patrol behaviour in wild chimpanzees. Animal Behaviour 70: 1079-1086.

Montgomery, E. and A. Johnson 1976. Machiguenga energy expenditure. Ecology of Food and Nutrition 6: 97-105.

Ohtsuka, R., N. Sudo, M. Sekiyama, et al. 2004. Gender difference in daily time and space use among Bangladeshi villagers under arsenic hazard: application of the compact spot-check method. Journal of biosocial science 36: 317-332.

Panter-Brick, C. 1996. Seasonal and sex variation in physical activity levels of agro-pastoralists in Nepal. American Journal of Physical Anthropology 100:7-21.

Paolisso, M. and R. Hames (in press) Methods for the systematic study of human behavior. Field Methods.

Peregrine, P., D. R. Drews, M. North, and A. Slupe 1993. Sampling techniques and sampling error in naturalistic observation: an empirical evaluation with implications for cross-cultural research. Cross-Cultural Research 27: 232-246.

Scaglion, R. 1986. Importance of nighttime observations in time allocation studies. American Ethnologist 13: 537-545.

Stange, K., S. Zyzanski, T. Fedirko Smith, R. Kelly, et al. 1998. How valid are medical records and patient questionnaires for physician profiling and health services research? A comparison with direct observation of patient visits. Medical Care 36: 851-867.

Sugawara, K. 1988. Visiting relations and social interactions between residential groups of the Central Kalahari San: hunter-gatherer camp as a microterritory. African Study Monographs 8: 173-211.

Takada, A. 2005. Mother-infant interactions among the !Xun : analysis of gymnastic and breastfeeding behaviors, In B. Hewlett and M. Lamb, eds., HunterGatherer Childhoods : Evolutionary, Developmental and Cultural Perspectives. New Brunswick, NJ: Transaction Publishers, pp. 123-144.

Turke, P. 1989. Evolution and the demand for children. Population and Development Review 15: 61-90.

Umezaki, M., T. Yamauchi, and R. Ohtsuka 2002. Time allocation to subsistence activities among the Huli in rural and urban Papua New Guinea. Journal of Biosocial Science 34: 133-137.

Yasuoka, H. 2006. Long-term foraging expeditions (Molongo) among the Baka hunter-gatherers in the northwestern Congo Basin, with special reference to the Wild Yam Question. Human Ecology 34: 275-295.

Veblen, T. 1899. The Theory Of The Leisure Class. An Economic Study in the Evolution of Institutions. New York: Macmillan.

Winking, J., M. Gurven, H. Kaplan, and J. Stieglitz 2009. The goals of direct paternal care among a South Amerindian population. American Journal of Physical Anthropology 139: 295-304. 